\title{
The Normativity of Meaning Defended
}

\section{Daniel Whiting}

The definitive version of this article is published in Analysis 67.2 April 2007 pp. 133-140 by Blackwell Publishing, and is available at www.blackwell-synergy.com.

\section{Introduction}

Meaning, according to a significant number of philosophers, is an intrinsically normative notion. ${ }^{1}$ For this reason, it is suggested, meaning is not conducive to a naturalistic explanation. In this paper, I shall not address whether this is indeed so. Nor shall I present arguments in support of the normativity thesis (see Glock 2005; Kripke 1982). Instead, I shall examine and respond to two forceful objections recently (and independently) raised against it by Boghossian (2005), Hattiangadi (2006) and Miller (2006). Although I shall argue that the objections are unsuccessful, they are worth attending to, not only because the normativity thesis is so widely accepted and is thought to have such ramifications but, most importantly, because doing so offers the opportunity to help clarify how it is to be understood. $^{2}$

\footnotetext{
${ }^{1}$ See, e.g., Alston 2000; Baker and Hacker 2004; Blackburn 1984; Boghossian 1989; Brandom 1994; Gibbard 1994; Glock 2005; Kripke 1982; Lance and O’Leary Hawthorne 1998; McDowell 1998: ch. 11; Putnam 1991: 11ff.; Wright 1992; Waismann and Wittgenstein 2003: 87ff.

${ }^{2}$ Of course, there are other arguments against the claim that meaning is intrinsically normative (e.g. Horwich 2005: ch. 5), but assessing them is beyond the scope of this paper. For a response to Davidsonian objections, see Glock 2005 and Whiting forthcoming.
} 


\section{$2 \quad$ What makes a statement normative?}

If meaning is an intrinsically normative notion, then one would expect statements about what an expression means to be normative, or to immediately imply a normative statement. What, then, makes a statement normative? Clearly not just that it contains normative vocabulary. The following appears to be a purely descriptive sentence, despite containing an evaluative term:

(1) Most people in Cornwall accept that murder is wrong. Correlatively, although the following has the surface form of a description, it might be used to express a rule and hence might be normative (albeit implicitly):

(2) The starting-position of a rook is a corner square.

Hattiangadi suggests that what is distinctive of normative statements is that they 'tell us what to do, whereas non-normative statements simply describe how things are' (2006: 221). This criterion, however, is unduly narrow. Not only might a normative statement tell us what to do, but also what we may or may not do. Notably, in all these respects normative statements are action-guiding.

So, to say that meaning is a normative notion is to say that a statement of what an expression means is, or immediately implies, a statement about what we ought (not) to or may (not) do with that expression. Although this no doubt requires supplementation and refinement, it is sufficient for present purposes.

\section{Correctness}


What underwrites the claim that meaning is intrinsically normative, and what does it amount to? A starting-point is the observation that, from the fact that a word has a particular meaning, it appears to follow trivially that it possesses conditions of correct application. This seems to be utterly platitudinous. As Hattiangadi writes:

... it hardly seems open to us to deny that in order to have meaning, terms must have correctness conditions. This is what distinguishes the use of language from the making of mere noise. (2006: 222)

Hence, it is reasonable to take the normativity thesis to involve a commitment to the following principle, where ' $w$ ' is a word, ' $F$ ' gives its meaning, and ' $\mathrm{f}$ ' is that feature in virtue of which $w$ applies:

(C) $\quad w$ means $F \rightarrow \forall x(w$ applies correctly to $x \leftrightarrow x$ is $f)$

According to $(\mathrm{C})$, to say that meaning is normative is to say that for an expression to have a meaning is for it to possess conditions of correct application.

The first thing to note is that if 'applies correctly to' expresses a norm then it is what one might call a word-world norm. That is, it specifies how an expression correctly applies to features of reality, and so is equivalent to 'is true of' ${ }^{3}$ Many proponents and detractors of the normativity thesis alike suppose that, if there are norms of meaning, then they are norms of truth. Horwich, for example, claims that any norm in this area would be that 'one ought to think what is true' (1998: 187; cf. Boghossian 1989: 513). In my view, although norms of truth might well govern the practice of assertion, the norms

\footnotetext{
${ }^{3}$ Alternatively, one might view 'correct' in this instance as equivalent to 'evidentially warranted'. I shall set aside this alternative and focus on the orthodox truth-theoretic conception. Nothing in what follows turns on this.
} 
determinative of meaning should be viewed as quite distinct. Nonetheless, for present purposes I shall waive this concern, as it does not bear on what follows.

Boghossian and Hattiangadi happily concede a principle such as (C), but claim that this does not get us normativity in the required sense (i.e. in a way that might pose problems for naturalism). Boghossian states that

it is not clear that, at least as it is being used here, 'correct' expresses a normative notion, for it may just mean 'true'. (2005: 207)

Hattiangadi elaborates a similar point, claiming that statements of correctness-conditions are descriptive not prescriptive; they do not tell us what to do but supply 'a description of [a speaker's] uses of $[w]$ as those that are "correct" and those that are "incorrect" '. Moreover, she continues:

Sometimes to say that something is right [i.e. correct] does not imply a prescription; rather, it is say that it meets a certain standard ... To say that some use of a term is 'correct' is thus merely to describe it in a certain way - in light of the norm or standard set by the meaning of the term. (2006: 223-25)

In response, recall first that, as already pointed out, in order to be normative a statement need not have immediate implications for what one ought to do. It is sufficient that it imply a statement about what may be done.

Second, and more significantly, it is indeed the case that whether something qualifies as 'correct' (by meeting a standard) is a matter of what descriptions are true of it, and so what properties it as a matter of fact possesses. Correlatively, if one knows the norm governing the use of a certain expression, then, from the statement that any particular 
application of it is correct, one can derive the descriptive statement that it possesses suchand-such features. Nevertheless, contra Boghossian and Hattiangadi, that a given use does in fact meet a certain standard is clearly a normative or evaluative matter; in addition to the descriptive statement it also immediately implies a statement about what one ought to or may do.

To support this contention and make it more concrete, consider the analogy Hattiangadi offers in support of her claim:

... think of theme park rides where there is a minimum height requirement for some of the more dangerous rides. This is a standard children must meet if they are to go on the ride. But however happy [a child] may be to meet the standard, whether or not she does is a straightforwardly non-normative, natural fact. (2006: 224)

It is true that, in order to meet the standard, and so for her going on the ride to satisfy the conditions of correctness, certain descriptions must be true of a child, namely that she is sufficiently tall. That is, certain 'straightforwardly non-normative, natural facts' must hold, and can be derived from the statement that she satisfies the relevant norm. Nevertheless, given that the standard is in force, that the child does as a matter of fact meet it (or fails to) certainly has implications for whether or not she may (or should not) go on the ride. If she were to do so incorrectly, with the norm in place, sanctions or criticism of one form or another would be appropriate. Hence, the norm is action-guiding, and to say that there are correctness-conditions for a child's going on a ride is to say that going on that ride is a normative matter.

Likewise, if a statement about the meaning of an expression does indeed imply that there are conditions for its correct application, as Boghossian and Hattiangadi accept, then it 
equally has implications for whether it may or should be used in certain ways. I shall not argue for the antecedent of this conditional here, but if it really is platitudinous, then it is platitudinous that meaning is normative. Boghossian and Hattiangadi are wrong to claim that one can accept a principle such as (C) without thereby accepting the normativity thesis.

Note that nothing said in this section implies that truth itself is a normative notion. If it is correct for a person to go on a ride only if that person is $4 \mathrm{ft}$ or taller, then being $4 \mathrm{ft}$ or taller makes it correct. Obviously, however, that property is a non-normative one. Likewise, if being true makes the use of an expression correct (according to the standard set by meaning), it does not follow from that fact alone that being true is a normative property.

\section{$4 \quad$ Prescriptivity}

Having rejected $(\mathrm{C})$ as capturing the content of the claim that meaning is intrinsically normative, Hattiangadi offers an alternative on behalf of its proponent (2006: 226):

(P) $\quad w$ means $F \rightarrow \forall x$ ( $w$ ought to be applied to $x \leftrightarrow x$ is $f$ )

According to $(\mathrm{P})$, statements about meaning immediately imply a prescription, and not merely a statement of correctness-conditions.

In the previous section, I argued that $(\mathrm{C})$ is indeed normative in the sense required for advocates of the normativity thesis. Nevertheless, it is worth considering (P) since, first, many philosophers have in mind such a principle when discussing the normativity of 
meaning (e.g. Hohwy 2001: 9-10). Second, (P) implies (C), and (C) in turn implies the corresponding principle:

(P*) $\quad w$ means $F \rightarrow \forall x$ (w ought not to be applied to $x \leftrightarrow x$ is not $f$ ) Thus, if there are problems with the idea that statements about what an expression means imply prescriptive statements concerning its use, then there would in turn be problems for the idea that expressions have conditions of correct use.

Of course $(\mathrm{P})$ as stated is obviously false. Given what it means, one is not obliged to employ an expression such as 'dog' to all dogs. Indeed, doing so is not even possible and, in so far as ought implies can, there can be no such requirement.

Since $(\mathrm{P})$ is to be rejected, one who holds that meaning is an intrinsically normative notion might instead advocate the following:

$\left(\mathrm{P}^{* *}\right) \quad w$ means $F \rightarrow \forall x$ ( $w$ ought to be applied to $x \rightarrow x$ is $f$ )

According to $\left(\mathrm{P}^{* *}\right)$, if 'rich' means rich then 'rich' ought to be applied to something only if that something is rich. Norms of this kind are action-guiding, and allow one to evaluate the use of expressions as right or wrong.

However, Hattiangadi argues that even principles of the form expressed by $\left(\mathrm{P}^{* *}\right)$ do not hold:

Under some circumstances, I might be obligated to tell a lie, which does not imply that I mean something non-standard by my expressions. (2006: 227)

Imagine a person's life will be saved if I apply the term 'rich' to one who is poor. It would seem that I ought to do so, but it hardly follows that 'rich' no longer means rich. It 
appears, therefore, that once unpacked as involving a commitment to $\left(\mathrm{P}^{* *}\right)$, the claim that meaning is intrinsically normative becomes decidedly less convincing.

It is certainly the case that one can imagine circumstances in which one is required to use an expression in a way that fails to accord with its standard meaning, without it following that the expression has a non-standard meaning. But to say that meaning is normative is only to say that expressions are governed by distinctively semantic proprieties. One can hold this while acknowledging that such norms might be trumped by other normative considerations, say ethical, epistemic, or prudential. That, all things considered, I am obliged to use an expression in a way that does not accord with its meaning is perfectly compatible with the fact that there is a semantic norm that speaks in favour (or against) a particular use of an expression, and in virtue of which that expression means what it does. Another way to put this point is to say that the norms of meaning generate prima facie obligations.

\section{$5 \quad$ Prima facie obligations}

One might complain, however, that this is equally implausible. As Hattiangadi points out, prima facie obligations are only overridden by other obligations, but it appears that alleged semantic obligations can be overridden by mere desires (2006: 232). For example, if I have no desire to tell the truth, I have no obligation to use 'rich' of a person only if she is rich. Consider also the contrapositive of the consequent of $\left(\mathrm{P}^{* *}\right)$ :

$$
\text { (P***) } w \text { means } F \rightarrow \forall x(x \text { is not } f \rightarrow w \text { ought not to be applied to } x)
$$


Does this, without qualification, hold? Imagine, for example, that Sabrina is poor. Does it follow immediately, from that fact plus the fact that 'rich' means rich, that I should not apply the term 'rich' to her? The opponents of the normativity thesis think not. As Boghossian succinctly puts it, 'What if I feel like lying, or misleading my audience?' (2005: 207).

What such cases appear to show is that the norms determinative of meaning are, at best, hypothetical; they are contingent on our desires. It follows that meaning is not intrinsically normative, that statements about meaning do not immediately imply prescriptive statements about what a person should (not) do with a word.

Moreover, the mere fact that there might be a hypothetical imperative concerning the use of an expression, given its meaning, is trivial. With a suitable desire, anything might be normative in this sense, and it certainly does not pose a problem for the naturalist. This is expressed by Boghossian, who writes that any normativity to meaning 'is mere hypothetical normativity, and that is uninteresting' (2005: 207). Likewise, Miller writes: The most that can be said is that if Neil means magpie by 'magpie' then given that he has a desire to communicate, or perhaps a desire to think the truth, or a desire to conform to his prior semantic intentions, he has a reason to apply 'magpie' to an object if and only if it is a magpie. Semantic reasons are at most only hypothetical reasons for action. (2006: 109)

Again, Hattiangadi insists that What might have looked like a prima facie obligation ... is more plausibly construed as a hypothetical obligation. (2006: 232) 
In response, surely a proponent of the normativity thesis would deny that the relevant semantic obligation can be overridden by desires alone. True, I might not follow the norm for the use of an expression simply because I do not feel like doing so. But that alone does not show that there is no norm in force; my use of the expression should still be judged incorrect. Of course, the violation is not very serious (the mistake is semantic, not ethical) but that does not establish that it lacks a normative status altogether.

This can be appreciated by comparing a putative semantic obligation with a paradigmatic hypothetical obligation. That I ought to go outside only if it is not raining is contingent upon my desire to stay dry. If that desire changes, I will not have done anything incorrect or failed to do as I should by going outside in the rain. Were I to do so, it would be unwarranted and make little sense to insist that, desire notwithstanding, my act was wrong.

In contrast, given what 'rich' means, that I ought to apply the term to a person only if she is rich does not seem contingent upon (say) my desire to speak truthfully. If that desire changes, and I apply the term to a poor person, it remains the case that I am not applying it as it should be applied, but rather incorrectly. Here, it seems one is properly entitled and it makes full sense to judge that, desire notwithstanding, I am using the expression wrongly. (Of course, I could excuse my behaviour by citing the relevant desire, but that is not the same as overriding the norm.) 
So, unlike the case where an ethical obligation overrides the semantic obligation to employ an expression in a given way, it does not appear that a mere desire can do so. Hence, it has yet to be shown that any requirement to employ a word only if certain conditions obtain is contingent upon a speaker's desires. We have not yet been given reason to doubt that $\left(\mathrm{P}^{* *}\right)$ holds

\section{Conclusion}

I have defended the thesis that meaning is an intrinsically normative notion against recent objections from Boghossian, Hattiangadi and Miller. These objections purport to show that either meaning is not normative at all, or that it is not in any respect that might be thought to be troubling for the naturalist. In response, I have argued that statements about correctness-conditions are suitably normative, and moreover that no reason has been given to deny that what an expression means generates (prima facie) requirements to use that expression in a certain way.

\section{References}

Alston, W. 2000. Illocutionary Acts and Sentence Meaning. Ithaca, New York: Cornell University Press.

Baker, G. and P. Hacker. 2004. Wittgenstein: Understanding and Meaning. New ed. Oxford: Oxford University Press.

Blackburn, S. 1984. The individual strikes back. Synthese 58: 281-301.

Boghossian, P. 1989. The rule-following considerations. Mind 98: 507-49.

Boghossian, P. 2005. Is meaning normative? In Philosophy - Science - Scientific 
Philosophy, ed. A. Beckermann and C. Nimtz. Paderborn: Mentis.

Brandom, R. 1994. Making it Explicit. Cambridge, Mass.: Harvard University Press.

Gibbard, A. 1994. Meaning and normativity. In Truth and Rationality, ed. E. Villanueva. Ascadero, California: Ridgeview.

Glock, H-J. 2005. The normativity of meaning made simple. In Philosophy - ScienceScientific Philosophy, ed. A. Beckermann and C. Nimtz. Paderborn: Mentis.

Hattiangadi, A. 2006. Is meaning normative? Mind and Language 21: 220-40.

Hohwy, J. 2001. Semantic primitivism and normativity. Ratio 14: 1-17.

Horwich, P. 1998. Meaning. Oxford: Oxford University Press.

Horwich, P. 2005. Reflections on Meaning. Oxford: Oxford University Press.

Kripke, S. 1982. Wittgenstein on Rules and Private Language. Oxford: Blackwell.

Lance, M. and J. O'Leary Hawthorne. 1998. The Grammar of Meaning. Cambridge: Cambridge University Press.

McDowell, J. 1998. Mind, Value, and Reality. Cambridge, Mass.: Harvard University Press.

Miller, A. 2006. Meaning scepticism. In The Blackwell Guide to the Philosophy of Language, ed. M. Devitt and R. Hanley. Oxford: Blackwell.

Putnam, H. 1991. Reality and Representation. Cambridge, Mass.: MIT Press.

Waismann, F. and L. Wittgenstein. 2003. The Voices of Wittgenstein, ed. G. Baker. Trans.

G. Baker, M. Mackert, J. Connolly and V. Politis. London: Routledge.

Whiting, D. Forthcoming. Meaning, norms, and use: critical notice of Language, Truth, and History by Donald Davidson. Philosophical Investigations.

Wright, C. 1992. Realism, Meaning and Truth. 2nd ed. Oxford: Blackwell. 